\title{
Dry Ice Cleaning Based Sustainable Cleaning Technology for Oil and Gas Storage Tanks
}

\author{
Ahmad Jassim $^{1}$ and hassanein Khalaf ${ }^{2}$ \\ ahmadkj1966@yahoo.com ${ }^{1}$, hassanein.khalaf@uobasrah.edu.iq ${ }^{2}$ \\ Research \& Development Department, SCIS, Iraq, Basra ${ }^{1}$, \\ Mechanical engineering Dept., College of Eng., University of Basra, Iraq, Basra ${ }^{2}$
}

\begin{abstract}
Traditional cleaning techniques may present risks for workers' healthiness and safety. A huge amount of dust generated through abrasive blasting from the substrate and abrasive can lead to serious health hazards such as lung cancer, skin burns, eye lesions, excessive noise and undesired waste. In this paper, dry ice cleaning technology is presented to mitigate the disadvantages of the traditional blasting methods. It is a solid form of carbon dioxide that accelerated with a very low temperature of $-78.5^{\circ} \mathrm{C}$ which sublimated directly after the attack the surface and goes to the atmosphere without leaving any waste. Therefore, dry ice blasting is used in many environmentally damaging solvent to remove a wide range of materials such as paint, oil, wax, bitumen and synthetic residues without damaging the surface. It is a sustainable process that minimizes the negative environmental impact and safe employees and equipment. For that reason, dry ice cleaning can be considered as environmentally friendly cleaning technology suitable for cleaning oil and gas storage tanks.
\end{abstract}

Keywords: Dry Ice Cleaning, Sand Blasting, Sustainable manufacturing, Oil Tank.

\section{Introduction}

Blasting is defined as an acceleration of particles by air or mechanical means to a surface or workpiece to achieve a variety of physical effects. There are two types of blasting and cleaning can be categorized as conventional and non-conventional blasting technology. This paper will introduce sandblasting technology as conventional blasting and dry ice cleaning as non-conventional blasting and cleaning technology that overcome all health and environmental problems which can be defined as a sustainable blasting technology.

\section{Traditional blasting technology}

Abrasive blasting is the traditional blasting technology that used to clean and blast substrates. It defines as a means forcing a stream of abrasive material with high velocity against a surface using compressed air, liquid, steam, centrifugal wheels to clean an object or surface, remove burrs, apply a texture or prepare the surface for painting or coating, etch and change the appearance of the surface. Traditional blasting technology is used in a wide range of industrial applications for cleaning surface of steel, bricks, cement and concrete materials. The process used a variety of media like aluminum oxide, steel shot, garnet sand, coal slag, silica sand, nickel 
slag, copper slag and iron ore [1-3]. Abrasive blast cleaning technology can be considered to be a cost-effective method that is more rapidly than pickling, electrochemical cleaning [4]. Sandblasting method with its potential health and safety hazards will explain as traditional abrasive blasting technology.

\subsection{Sandblasting}

Sand is the most commonly utilized abrasive material than other types of abrasive materials. Sandblasting is the same as spray painting but instead of paint, you blow on abrasive material with compressed air or liquid to etch the surface being blasted. Moreover, it is called abrasive blasting which can be well-defined as the operation of forcibly pushing a stream of abrasive material against a surface under high pressure to smooth a rough surface, roughen a smooth surface, shape a surface and remove the contaminate [4].

\subsection{Health hazards}

The most significant health hazards that happened by using abrasive materials are including dust, noise and chemical [4].

Dust. Dust can be considered as the most serious health hazard in abrasive cleaning and blasting operations. It results from broken down abrasive and from an object being blasted as solid particle dust with size in the range of (1-1000) microns or more. Dust with particle size more than 10 microns will be settling quickly. However, dust with a size of fewer than 10 microns will stay flying longer. It is breathed in easily and settled in the lungs as well as the smallest parts dissolve into the bloodstream. Moreover, dust may be affected by the nearest working area because of its air-bone and heavily concentrated dust which depends on the ventilation system, wind condition and humidity. Therefore, dust can generate a health risk for unprotected workers after settlement when they give the task of beating dust collector bags [4].

Noise. Noise is health hazards generated from blasting abrasive materials as a sound which can create a serious impact on workers lead to hearing loss.

Chemical. The blasting operation may be used to clean a surface mainly on a greasy surface with a chemical material like trichloroethylene and methylene chloride which leads to serious health hazards. Health hazards are happened due to inhalation vapors, ingestion and skin engagement of liquid.

\subsection{Safety hazards}

The majority of safety risks that happened due to applied abrasive blasting include visualization injury or impairment, sliding, flying abrasive, fire and static electricity [4].

Vision impairment. It has happened when dense cleaning dust developed and flow around the operator and work area. This generates vision or visualization injury which may lead to a bad accident due to insufficient air in the working site. 
Slipping hazard. It has happened when the cleaning and blasting dusts settled on the floors of work sites which leads to serious.

Fire hazards. It has happened when iron oxide dust generated by the abrasive cleaning process is mixed with fine aluminum dust.

\section{Sustainable blasting technology}

Sustainable manufacturing process can be defined as the creation of manufacturing products that use processes to minimize the negative environmental impact, conserve energy and natural resources as well as it is a promising technology help to eliminate waste, cost and pollution [5, 6 ]. The non-conventional blasting materials that have less toxic include ice cubes, dry ice, plastic bend media, sponge, sodium bicarbonate, water, biodegradable materials [3]. Dry ice blasting and its benefits will present as sustainable and non-conventional blasting technology comparing with the sandblasting method. Sandblasting was done based on the mechanical impact of blasting media, however, dry ice cleaning is done based on thermal shock without destroying the properties of the substrate.

\subsection{Dry ice cleaning}

Dry ice cleaning is one of the main sustainable cleaning technologies that can be used to clean and blast substrate which used carbon dioxide as dry ice materials without using any abrasive materials. It is a highly effective and environmentally friendly process that uses to clean surface contamination. Dry ice blasting can be considered as a successful way for many applications containing heavy bitumen and oil accumulation to surface preparation for non-destructive examination in up, mid and downstream environment as well as automotive, machinery and food industry. Carbon dioxide can be considered as a non-poisonous, liquefied gas, nonconductive and non-flammable gas which is easily stored at worksites and inexpensive. It has the main properties and shape shown in table land figure 1. Liquid carbon dioxide can be applied to produce dry ice pellets by using a pelletizing machine. The liquid is expanded under controlled conditions to produce and form dry ice snow. Then the snow is pressed through an extruder plate into a round to produce hard snow pins with a diameter of 2-3 mm and length of 2.5-15 $\mathrm{mm}$ as dry ice. A huge amount of forced air with high pressure is required to accelerate the particles of dry ice during the cleaning process. It is a very expensive form of energy employed in the industrial fields. [7].

Table 1. Properties of Carbon Dioxide (CO2) [8].

\begin{tabular}{lll}
\hline Specification & Unit & Values \\
\hline Molecular Weight & $\mathrm{g} / \mathrm{mole}$ & 44.1 \\
Density (Solid) at $-78.5^{\circ} \mathrm{C}$ & $\mathrm{Kg} / \mathrm{m}^{3}$ & 1.562 \\
Density (Liquid) at $-18^{\circ} \mathrm{C}$ & $\mathrm{Kg} / \mathrm{m}^{3}$ & 1.022 \\
Density (Gas) at $0{ }^{\circ} \mathrm{C}$ & $\mathrm{Kg} / \mathrm{m}^{3}$ & 1.977 \\
Melting Point (triple point at 5.2 bar) & ${ }^{\circ} \mathrm{C}$ & -56.5 \\
Boiling Point (sublimates) & ${ }^{\circ} \mathrm{C}$ & -78.5 \\
Liquid-to-Snow Conversion Rate at $-17.6^{\circ} \mathrm{C}$ & $\mathrm{Kg}$. snow $/ \mathrm{kg}$. liquid & 0.46 \\
\multicolumn{1}{r}{ at $-47.8^{\circ} \mathrm{C}$} & $\mathrm{Kg}$. snow $/ \mathrm{kg}$. liquid & 0.57 \\
\hline
\end{tabular}




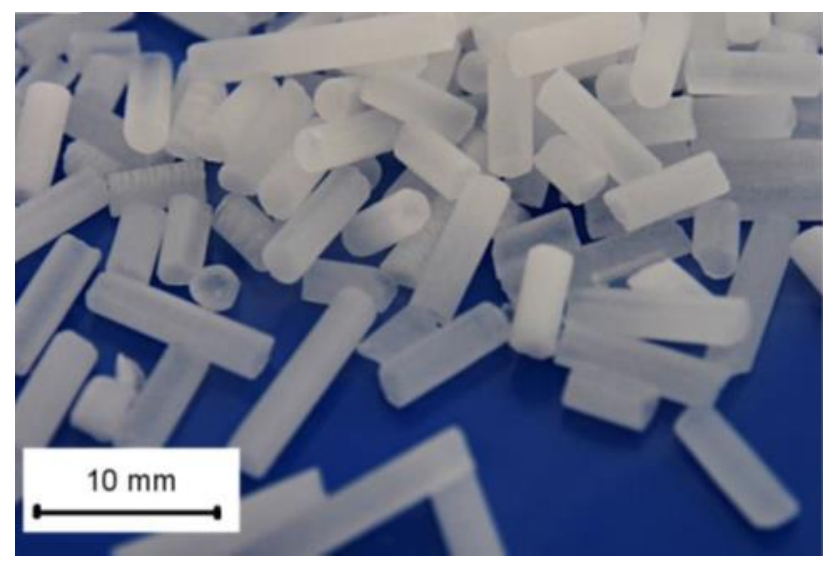

Fig. 1. Dry ice pellets (solid carbon dioxide) [7]

The main advantages of dry ice cleaning and blasting can be summarized as [7-12]:

1. Different kinds of decontamination can be removed.

2. Carbon dioxide pellets have good insulation properties with no flashover accident.

3. Quicker process that reduces downtime and increases production time.

4. Does not produce secondary waste, residue and moisture.

5. No contamination happens during the blasting process.

6. Does not add additional $\mathrm{Co} 2$ to the atmosphere.

7. The process reduces labor and resource.

8. Soft media that not harm the substrate.

9. Zero waste products

10. Environmentally responsible

11. Food grad media.

12. Safe operation.

13. High efficiency.

As same as conventional blasting method, there is some factors affected the efficiency of dry ice cleaning which can be summarized as below $[8,10,11]$ :
1. Air force.
2. Dry ice mass flow.
3. Attack angle.
4. Blasting distance.
5. Nozzle rotation speed. 


\subsection{Dry ice cleaning and blasting mechanism}

Dry ice cleaning can be defined as a sustainable cleaning process that applied a solid form of carbon dioxide which is comparable to other forms of grainy blasting such as sandblasting. However, dry ice pellets are used as the blasting medium which are speeded in a pressed air stream and focused at a surface to clean it. No chemical residue will leave because dry ice material will be sublimated at room temperature [13-16].

Dry ice attacking includes impelling pellets at exceedingly high speed. The real dry ice pellets are relatively soft and mush less dense than other means used in attacking and cleaning. During the impact process, the dry ice pellets will be sublimated directly and transferring minimal kinetic energy to the surface with minimum abrasion. A huge bulk of heat will absorb from the surface and thermal shock will happen during the sublimation process which produces shear stress on the surface which leads to developing the cleaning process. The upper layer of the pollutant is likely to transfer more heat than the underlying substrate and easily shaving off. Thermal conductivity of the substrate and contaminant affected the efficiency and effectiveness of the dry ice cleaning process. Moreover, the rapid change in the state of dry ice pellets as a sublimation process will cause minuscule shockwaves that help to remove the contaminant from the surface [13-16].

Dry ice cleaning can be considered as a function of the particle mass density and impact velocity because carbon dioxide particles have a relatively low hardness. The cleaning process relies on high particle velocities generated by the air stream to achieve the needed impact energy. Unlike other blast media, carbon dioxide pellets have a very low temperature equal to $-78.5^{\circ} \mathrm{C}$. This gives the dry ice cleaning process a unique thermodynamic behavior that affects the contamination in greater or lesser degrees depending on the contamination or coating type. Therefore, the material becomes brittle and the fraction or thermal shock will occur due to the different temperatures between dry ice pellets and material surface. The cleaning includes three processes $[8,13-16]$ :

1. Impact process: dry ice media impact the surface of the material through extremely high speed.

2. Embrittlement and warpage process: the temperature of surface dirt rapidly drops during the cleaning process due to the effect of dry ice pellets temperature which causing fractions and thermal shock.

3. Sublimate process: due to very low-temperature of snow ice pellets, the enter pollutions will crash and the particles sublimated directly to gas. The size of particles magnifies to 890 times in microseconds which removed as a fragment impurity. The flaking is detached by the ablation of pellets and the purgative shave of compacted air. 


\subsection{Dry ice cleaning machine}

Dry ice cleaning machines consist of four main elements that include an air compressor, blasting machine, transport of pellets, and blasting nozzle. Compressed air can be operated with pressure in the range of 1-20 bars with a consumption air rate of $18-420 \mathrm{Nm} 3 / \mathrm{h}$ and dry ice with consumption of $20-190 \mathrm{~kg} / \mathrm{h}$ [7].

\subsection{Application of dry ice blasting}

The main application of this technology can be summarized as below [9]:

1. Remove heavy oil, carbon and paraffin buildup.

2. Clean and prepare the surface for testing, maintenance and repair.

3. Reduce the risk of equipment failure for natural gas equipment.

4. Maintain high heat transfer (steam generation).

5. Clean nuclear power generator components.

6. Clean hydroelectric power equipment.

7. Clean in-place parts and equipment.

8. Clean substation equipment.

9. Clean power generators.

10. Clean heat exchangers.

\subsection{Potential Health and Safety Hazard}

Different cleaning methods can be applied to clean the sludge and rust of the oil storage tank which includes chemical and mechanical cleaning processes. The major disadvantages of these methods are generated highly dangerous pollution, corrosion and waste generation require cleanup. Moreover, they cannot be done only in opening space because their process makes the place dusty and noisy. However, dry ice cleaning produces fewer waste products and does not require cleanup of a blasting medium. It is a greener cleaning technology that applied without any damage, downtime, chemical residue, wear and tear because it is inflammable, electrically non conducting and chemically inert media. Moreover, dry ice blasting is a waterless method, non-corrosive, deep cleaning and microorganism removal, non-hazardous and non-abrasive process [13-16].

Dry ice cleaning can be used in different environmental solvent include trichloroethene, methylene chloride, perchlorethane, orthodichlorobenzine, cresylic acid and caustic solution. Furthermore, sensitive surface and electric components such as switchboard can be cleaned easily and smoothly. The pellets hit the object surface and cooled it with thermal shock at freezing temperature in a part of the second. The varnish, paint, contamination, and dirt contracts become brittle and crack which can be removed easily by pellets. Therefore, dry ice cleaning can be used to clean oil and gas storage tanks without any problems [13-16].

\section{Conclusions}

- There is a possibility to use carbon dioxide pellets as a dry ice cleaning process to clean oil and gas storage tanks instead of the abrasive blasting process. 
- Dry ice cleaning is a green and sustainable cleaning process that minimizes the negative environmental impact, conserve natural resources and safe employees and equipment.

- Dry ice cleaning process can be considered as an environmentally friendly method comparing with the sandblasting method because sandblasting had health and safety hazards such as dust, noise and chemical that affected the health of workers. However, dry ice cleaning does not have these hazards.

- Dry ice cleaning can be considered as a successful way for many applications containing heavy bitumen and oil accumulation to surface preparation for non-destructive examination in up, mid and downstream environments.

- Dry ice cleaning does not require cleanup of a blasting medium while sandblasting media need to be clean up after blasting.

\section{References}

[1] Abrasive blasting, safe work Australia, 2012, www.safeworkaustralia.gov.au

[2] Zakaria, A., Asmuin, N., Halim, N., and Farid, M.: Dust monitory exposures: abrasive blasting process. International Journal of Engineering and Technology. Vol. 8, No. 6, pp. 2537-2540 (2017)

[3] OSHA fact sheet: Protecting workers from the hazards of abrasive blasting materials. http://www.osha.gov

[4] Environ-management \& Research Inc.: Abrasive blasting operations, US department of health education and welfare, Washington D. C printer, (2001)

[5] Jassim, A. and Hammood, A.: Sustainable manufacturing process for bulk metallic glasses production using rapid solidification with melt spinning technique. International Conference on Material Science and Material Engineering MSME2014 (2014)

[6] Jassim, A.: Using sustainable manufacturing process to produce solid shaft from Al-Zn alloys chips and copper chips without melting. Elsevier, Science Direct, Procedia CIRP. Vol. 40, pp. 1317 (2016)

[7] Máša, V. and Kuba, P.: Efficient use of compressed air for dry ice blasting. Journal of Cleaner Production. Vol.111, No. A, pp.76-84 (2015)

[8] Chen, J., Mu, H., Hu, Q., and Jiang, Z.: Investigation on the process of dry ice cleaning. IOP Conference Series: Materials Science and Engineering. Vol. 394 (2018)

[9] Dry ice blasting solutions. http://www.coldjet.com/dry-ice-blasting

[10] Shigeo, H. and Aoki, S.: Development of the insulator washer robot. International Conference on Robotics and Automation. IEEE. Vol. 2 (1995)

[11] Joon, P., Cho, B. and Byun, S.: Development of automatic cleaning robot for live-line insulators. 11th International Conference on Transmission \& Distribution Construction, Operation and Live-Line Maintenance (ESMO 2006). IEEE, USA (2006)

[12] Millman, L. and Giancaspro, J.: Environmental evaluation of abrasive blasting with sand, water, and dry ice. International Journal of Architecture, Engineering and Construction. Vol. 1, No. 3, pp. 174-182 (2012)

[13] Yang, LIU. : "Application status and prospect of dry ice cleaning in China". Cleaning World (2006).

[14] LU, H., XU, H., LI, C and CUI, Z.: "Application of Carbon Dioxide Ice Cleaning in Removing Iron Core Corrosion of the Generator". Zhejiang Electric Power (2013)

[15] Spur, G., Uhlmann, E. and Elbing, F.: Dry-ice blasting for cleaning: process, optimization and application. Wear 233, pp. 402-411 (1999).

[16] Zhen , L., Feng, J., Jun, Z. And Jian, Z.: The Development and the Field Application of the On-line Dry Ice Washing Vehicle System. Applied Mechanics and Materials. Trans Tech Publication. Vol. 615, pp. 58-65 (2014) 
